\title{
Los Coristas. Análisis Psicoestético y Socioeducativo de un Filme Francés
}

\section{The Chorus. A Psychoaesthetic and Socioeducative Analysis about a French Film}

\author{
Eduardo Llanos Melussa * \\ Universidad Diego Portales, Chile
}

\begin{abstract}
Se ofrece un análisis de Los coristas (Les choristes), película francesa que presenta un caso de intervención e innovación pedagógica con niños en riesgo social. Se examinan seis dimensiones del filme (interpersonal, intrapersonal, transpersonal, ideológica, simbólica y estética), y los comentarios cubren seis niveles de comprensión y apreciación (descriptivo, inferencial, interpretativo, valorativo, introspectivo y heurístico o creativo). Aunque el ejercicio sigue un modelo propio, en su elaboración confluyen varios aportes: educación por el arte, enseñanza para la comprensión, pragmática de la comunicación, enfoque sociocultural y sociocrítico de la educación, narratología cognitiva y enfoque cognitivo-evolutivo de Parsons. El artículo incluye también un apartado con reflexiones metacríticas y otro con sugerencias concretas aplicables al ámbito de la educación inclusiva. En ambos casos se procura extraer lecciones implícitas del filme (cuyo protagonista es un educador motivador, creativo e integrativo), extrapolándolas a una suerte de método útil y al menos parcialmente replicable.
\end{abstract}

Descriptores: Abandono infantil; Actitud del docente; Innovación educacional; Integración escolar; Proceso de interacción educativa.

This article analyzes the French film The chorus (Les choristes), in which a pedagogical intervention and innovation with children at social risk is presented. Six dimensions of the film are examined (interpersonal, intrapersonal, transpersonal, ideological, symbolic, and aesthetic), and the analysis approaches six levels of comprehension and appreciation (descriptive, inferential, interpretative, valorative, introspective, and heuristic or creative). Although the analytic exercise is based on an original perspective, in its elaboration several contributions converge: the education by art, the teaching for understanding, the pragmatics of communication, the sociocultural and sociocritical focus on education, cognitive narratology, and the cognitive and evolutive perspective of Michael J. Parsons. The article includes a section with metacritical reflections, and a last part that offers specific suggestions to apply at the field of the inclusive education. In both cases, we try to extract some implicit lessons from the film (whose protagonist is a motivating, creative and integrative educator), extrapolating those lessons by to a kind of a useful and at least partially replicable method.

Keywords: Abandoned children; Teacher attitudes; Educational innovations; School integration; Educational interaction process. 


\section{Introducción}

Por su interés socioeducativo, Los coristas merece un abordaje interdisciplinar, que aproveche aportes de la psicología, las humanidades y la pedagogía. En este caso, después de una ficha técnica elemental y una breve sinopsis (sección II), ofrecemos un análisis en seis dimensiones (sección III): interpersonal, intrapersonal, transpersonal, ideológica, simbólica y estética, tomadas del modelo de análisis psicocinematográfico (Llanos, 2002; 2016; 2017a; 2017b). En cada dimensión se formulan comentarios de distintos niveles: $\left[1^{\circ}\right]$ observaciones descriptivas, que remiten a escenas observables; $\left[2^{\circ}\right]$ inferencias, que se apoyan en lo observable, pero lo trascienden; $\left[3^{\circ}\right]$ interpretaciones, que oscilan entre lo presumible y lo plausible; [4 ${ }^{\circ}$ ] juicios valorativos, que consideramos fundados; [5 ${ }^{\circ}$ ] comentarios introspectivos y metacognitivos, pues cada analista bien puede autoexplorarse a propósito del filme; $\left[6^{\circ}\right]$ extrapolaciones heurísticas o creativas, ya que examinar cuidadosamente una obra creativa suele suscitar o estimular la creatividad o al menos la imaginación del espectador.

Ascendiendo a un nivel más abstracto, la sección IV introduce ciertas reflexiones metacríticas, y la sección $\mathrm{V}$ ofrece sugerencias concretas para aplicar el modelo al ámbito de la educación inclusiva.

\section{Ficha técnica y sinopsis}

Título: Los coristas $[$ Les choristes $]$.

País y año: Francia, 2005.

Dirección: Christophe Barratier.

Género: Drama.

Música: Bruno Coulais.

Guión: Christophe Barratier, Philippe Lopes-Curval.

Producción: Francia, Suiza, Alemania, 2004.

Duración: 95 minutos.

Sinopsis: La película comienza en Nueva York, a inicios del siglo XXI. Pierre Morhange, afamado director de orquesta, recibe poco antes de un concierto la noticia de la muerte de su madre. Vuela entonces a Francia, su patria, para asistir al funeral. Allí lo visita un hombre de su edad, que lo reconectará con un período clave de su infancia. Se trata de Pepinot, ex compañero de Le Fonde de l'Etang, un internado para niños difíciles o en riesgo social (posiblemente huérfanos de postguerra), donde ambos habían estudiado medio siglo antes. Pepinot entrega a Morhange el diario de vida de Clement Mathieu, un profesor de música que en 1949 trabajó allí como preceptor. Al leer el diario de ese maestro difunto, Morhange revive sus días en aquel reformatorio, su inicio en la música y su triste condición de cuasi huérfano.

En el reformatorio imperaba una tensión carcelaria y sin esperanzas. Rachin, director del establecimiento, imponía un estilo despótico y represivo (que él llamaba "acción-reacción") para imponer el control y la disciplina. Bajo esa jefatura autoritaria, el resto del personal no mostraba calor humano ni trataba a los internos con espíritu realmente pedagógico 
(excepto el amable Maxence, un viejo auxiliar que fungía como vigilante, enfermero, repostero, vidriero y jardinero). Además, los niños eran indisciplinados y agresivos.

Sin embargo, las dificultades no amilanan a Mathieu. Introduce gradualmente un estilo distinto, creativo y personalizado. Previsiblemente, Mathieu entra en conflicto con el director, reacio a cualquier innovación pedagógica. Pese a todo, valorando a cada alumno e instando a todos a dar lo mejor de sí, Mathieu logra crear un coro.

Por cierto, este docente por vocación debe afrontar numerosos desafíos. Ya en su primera visita al colegio encontrará junto a la reja a un pequeño (Pepinot), que espera melancólicamente a unos padres que nunca lo visitan; seguidamente, verá otro niño trapeando el piso como penitencia; luego presenciará cómo Maxence -el más comprensivo de los empleados- termina herido en el rostro por una "broma"; finalmente, descubrirá que, a fin de averiguar quién había hecho la "broma", el director estimula la delación y castiga a un pequeño inocente. Por cierto, los días posteriores mostrarán más y más síntomas de esta patología institucional.

Pero nuestro tesonero protagonista se consagra por entero a su trabajo pedagógico, que tiene mucho de parentalidad sublimada, de musicoterapia y hasta de evangelización indirecta. Respeta todo lo posible a los niños, aun si ellos abusan de su paciencia; sin embargo, introduce cierta disciplina combinada con sentido del humor y justicia. Así logra transformaciones graduales, que repercuten también entre sus colegas, y hasta el propio director muestra cambios episódicos (aunque vuelve pronto a su inveterado autoritarismo).

Entre los estudiantes, Morhange es uno de los más intratables, pero también el de mejor voz. Mathieu sabe bien que ese talento vocal es un diamante en bruto, y procura pulirlo (de hecho, le gestiona una audición en un conservatorio de prestigio). Al mismo tiempo, se siente atraído por la madre de Morhange y busca pretextos para interactuar con ella. Lamentablemente, no es correspondido.

La admisión irregular de un joven inadaptado pone en riesgo el proyecto de Mathieu. Se trata de Mondain, un muchacho de rasgos psicopáticos, cuyas amenazas y actitudes desafiantes tensan aún más el ambiente. El director lo castiga severamente y lo inculpa por un robo de dinero. En realidad, se trataba de una incriminación injusta, pues el robo lo había cometido otro alumno (a quien Mondain jamás delata).

Pese a todo, el coro va mejorando y afiatándose, y los efectos sociopedagógicos llegan a oídos de la baronesa que financia el reformatorio. Entusiasmada, convoca a una junta de los nobles de la ciudad a fin de aumentar los aportes. Precisamente mientras sesionan para decidir dicho aumento, ocurre un incendio que destruye parte del recinto. Todo indica que Mondain se ha cobrado venganza. Arguyendo que lo había dejado a cargo del establecimiento, el director responsabiliza a Mathieu y lo despide. Impotente, Mathieu debe marcharse sin poder siquiera despedirse de sus alumnos. Pero ellos sí se despiden: desde las ventanas le dirigen avioncitos de papel con mensajes llenos de reconocimiento, gratitud y cariño. El más pequeño (Pepinot) insiste en que lo lleve con él, y Mathieu finalmente accede. 


\section{Análisis en seis planos}

\subsection{Plano interpersonal}

Despotismo vs. albedrío. El director del establecimiento es punitivo, controlador e intransigente; en cambio, Mathieu es dialogante y afable. Tal contraste marca notoriamente sus interacciones con los estudiantes, con el viejo Maxence y los otros dos preceptores (Chabert y Langlois). Más que instruir, Mathieu educa; no es un profesor convencional, sino un artista que induce aprendizajes significativos y una notable colaboración.

Tensiones entre el docente y el director. El vínculo entre Rachin y Mathieu es tenso desde el inicio, pues Rachin subordina y descalifica. "Señor, acepte que la música no interfiere con la disciplina. Ahora tenemos menos problemas", dice Mathieu; sin embargo, Rachin atribuye el progreso a mera casualidad. "No creo en la casualidad", replica Mathieu. "Me doy cuenta”, remacha devualuativamente el director. Otro diálogo será todavía más tenso: "No me gusta su actitud", dice Rachin en tono admonitorio. "A usted no le gusta nada, señor", responde Mathieu, discrepando ya abiertamente.

Mendacidad y manipulación. Rachin miente a menudo: por ejemplo, dice a Chabert que Mondain ha confesado el robo, confesión que jamás ocurrió (ni siquiera para suspender el castigo físico que le aplicaba el director); asimismo, se arroga ante la baronesa $-\mathrm{y}$ en presencia del propio Mathieu- la idea de crear el coro; finalmente, oculta al comité de benefactores el maltrato que inflige a los niños.

Descalificaciones y circularidad viciosa. Si la mentira es ya un obstáculo interpersonal, Rachin agrega la descalificación. Por ejemplo, después de aceptar irresponsablemente la incorporación de Mondain como parte de un "experimento" psiquiátrico, confiesa arrepentido: "No debí aceptarlo..."; pero enseguida añade: "Igual que su música” (es decir, pone en un mismo nivel a un delincuente juvenil y a un profesor ejemplar). En otra escena, cuando unos niños le gritan obscenidades y escriben grafitos en su contra, Rachin atribuye todo a la nueva enseñanza ("El canto les desarrolla la mente, Mathieu"), inculpando a Mathieu de propiciar la rebeldía. "Llevan semanas sin agua caliente”, contesta Mathieu, insinuando que la conducta de los niños es una consecuencia comprensible ante la arbitrariedad, pues Rachin había impuesto las duchas frías como castigo por el robo del dinero. Incluso desde el conductismo más simple, tal represalia era injusta (pues castigaba a todos por igual) e ineficaz (ya que cohesionaba al grupo contra de la injusticia). Pero, ocupado como estaba de afirmar su poder, Rachin no percibía sus incongruencias. Era incapaz de reflexionar o de mantener siquiera un diálogo razonable: "El agua fría les activa la circulación", responde para "justificar" la represalia, y además contraataca: "Por cierto, Mathieu, olvídese del coro”. En efecto, suprime el coro, frustrando así un trabajo eficiente y bien inspirado. En suma, con su prepotencia y torpeza, Rachin provoca círculos viciosos, convirtiendo las dificultades en problemas y éstos en conflictos.

Reciprocidad. La relación de Mathieu con los internos es de progresiva cooperación. Si bien le pusieron un apodo apenas lo vieron ("Calva de cromo"), terminan regañando a Morhange después que éste le lanza la tinta en la cabeza. Se infiere entonces que, a la larga, su dedicación y su actitud comprensiva despertaban reciprocidad.

Desapego e inadecuación parental. Los niños del reformatorio parecen casi huérfanos; sus padres están ausentes o resultan tangenciales. Por ejemplo, aunque Morhange es visitado 
por su madre (Violette), todo indica que el hijo resiente el abandono. De hecho, Morhange no conoce a su padre, y las visitas casi protocolares de su madre no parecen consolarlo. El siguiente diálogo entre ella y Mathieu permite entender por qué el niño experimentaba pena y frustración.

-Pierre [Morhange] es muy sensible... y talentoso -comenta Mathieu.

- [talentoso] para actuar como idiota-retruca Violette.

Nótese la ambivalencia respecto al hijo: Violette le declara afecto, pero a sus espaldas lo descalifica. En tal sentido, Mathieu cumple un rol mediador, ya que se siente atraído hacia ella. Por ejemplo, hace ver a Morhange que, en caso de enterarse de su desobediencia de las reglas, Rachin lo castigaría: "Y quizás qué le diría a tu madre", agrega. "Me importa un bledo mi madre", responde Morhange", reincidiendo en la actitud de autoengaño que Mathieu le enrostra (es evidente que al muchacho le importaba mucho su madre, pues era lo único que tenía). Y para mayor desgracia de Morhange, el ingeniero con quien su madre se casa no llega a cumplir un rol parental con él; de hecho, intentó enviarlo a un internado. Ahora bien, recordemos que los otros niños sufren incluso más abandono que Morhange.

Creatividad versus hospitalismo. La creatividad de Clement contrasta con el frío hospitalismo que impera en el internado, y revierte los círculos viciosos con círculos virtuosos. Por ejemplo, Mathieu inviste a Morhange como encargado de la disciplina: "Me dijeron que los rebeldes son líderes. Demuéstrelo". Mathieu aún no lo conocía bien, pero de seguro recordaba la advertencia de Régent: "Morhange parece ángel, pero actúa como diablo". Pues bien, esa medida del profesor constituye toda una maniobra paradójica intuitiva, que técnicamente se conoce como 'prescripción del síntoma': viendo que Morhange aspira a ser líder, le asigna ese rol, pero al mismo tiempo lo desafía para que pruebe su liderazgo manteniendo la disciplina (y dado que colaborar es lo opuesto a sabotear, el joven afrontará una paradoja). ${ }^{1}$ Esta medida no convencional tiene otra virtud: cambia el patrón dominante en el internado, donde las relaciones se establecen y definen entre dos polos: protección versus ataque y descalificación.

La transformación emancipadora. Gradualmente, el protagonista se agencia el apoyo solidario del resto del personal, suscitando de paso una toma de conciencia respecto del despotismo de Rachin. Así, la cordial entrega de Mathieu no se reduce a mera eficacia pedagógica, pues también provoca efectos progresivos y de alcance sistémico.

\subsection{Plano intrapersonal}

Daños de la crianza. Como se sugirió más arriba, varios estudiantes parecen tener conflictos intrapsíquicos relacionados con sus padres. Por cierto, diversas escenas muestran que la indefensión vulnera más intensamente a los más pequeños.

Parentalidad sublimada. Dado que el filme no aporta indicios de que Mathieu tuviera hijos, cabe presumir que -ejerciendo como formador- él compensa o sublima una paternidad pendiente. Y como tampoco parece tener esposa, podríamos interpretar algo similar sobre

\footnotetext{
${ }^{1}$ Inspirados en la escuela de Palo Alto (aunque también en la "intención paradójica" introducida antes por Víctor Frankl), los psicoterapeutas sistémicos suelen afrontar las contradicciones patógenas de los pacientes adoptando medidas contraparadójicas, como "prescribir el síntoma". Esto deja al paciente en una situación extraña: si se resiste a seguir la instrucción, desaparece el síntoma, que es precisamente la meta del tratamiento; si sigue la instrucción, estará reconociendo implícitamente que tiene cierto control y que, por tanto, el síntoma no es del todo involuntario o inconsciente. Así, Mathieu aplica una "contraparadoja".
} 
su sexualidad: la sublima y transmuta en creatividad docente y musical. En tal sentido, constituye un personaje idealizado, aunque verosímil.

La violencia introyectada. En contraste, Rachin encarna una especie de superyó tóxico, pues en su rol de director se comporta punitivamente. Su rigidez sugiere que tampoco recibió suficiente cariño en su infancia.

Búsqueda de reconocimiento. Cada personaje busca reconocimiento; incluso el rebelde Morhange parece movido por el deseo de hacerse notar (y de hecho lo consigue durante la visita de la baronesa). Inicialmente, estas búsquedas se expresan con agresividad, pero luego se regulan hasta facilitar el autoconocimiento y el autocontrol de cada persona.

Autorrealización por el arte versus enajenación laboral. Para comprender la dinámica interior del protagonista, conviene distinguir al menos dos niveles: ciertamente, él estaba cesante y necesitaba trabajar; sin embargo, es significativo que no acepte cualquier trabajo, sino uno que le permite integrar su doble vocación: la educación y el arte. Motivado intrínsecamente, termina dignificando el humilde rol que desempeña. Contrasta así con el director, quien -en su última conversación con el protagonista- admite que no está a gusto en ese trabajo, pues deseaba otra clase de actividad. Asistimos entonces a dos modos opuestos de afrontar el trabajo: uno en pos de la autorrealización y orientado al bien común; otro alienado, improductivo y dañino.

El niño interior. La maduración vocacional de Mathieu se transmite a sus alumnos, en cuyos procesos también cabe distinguir niveles claramente diferenciados. $\mathrm{Al}$ inicio, cada interno busca a sus padres (reales o simbólicos), y su frustración provoca síntomas personales y psicosociales (rebeldía, agresividad, individualismo); más tarde los internos irán descubriendo el "niño interior" y alcanzarán cierta profundización espiritual, efecto propio del arte trascendente.

\subsection{Plano transpersonal}

Del conflicto a la colaboración. Al comienzo los niños mantienen relaciones conflictivas y competitivas; sin embargo, empiezan a cooperar en pos de metas compartidas: el coro, la música, el aprendizaje, el autodesarrollo. Además, los niños y el personal del centro logran unirse y oponerse al director, quien finalmente es despedido.

El sentido de cada quehacer. Todos los personajes (director, cuidadores, niños) realizan actividades sin sentido propio, como desconectados de su verdadera vocación; empero, esto cambia gradualmente y cada cual va encontrando un sentido más propio, personal y satisfactorio en sus quehaceres.

Maduración de los vínculos. Asimismo, la interacción evoluciona desde la intolerancia hacia la tolerancia, desde la rabia hacia la cooperación. Correlativamente, se incrementan el autocontrol y la autorrealización tanto de los niños como de varios adultos. El propio protagonista va empoderándose y arrostrando con asertividad el despotismo del director.

Pedagogía y psicagogía. El estilo pedagógico de Mathieu era también una psicagogía, una orientación del alma. "Gradualmente -anota en su diario-, mientras mi coro cobra forma, saco a mi cantante nuevo [Morhange] de su caparazón". Y más adelante se lo dirá directamente: "Morhange, aunque parezca raro, las cosas que haces no se parecen a ti: huir, pelear, fingir ser un matón”. Es decir, lo llama a deponer el falso 'sí mismo' y explorar su propia identidad. 
Potenciación mutua. A medida que descubren y desarrollan su creatividad personal y grupal, los niños progresan en autoestima, autoeficacia y autorrespeto. Evocando sus propios sueños, se motivan hacia el aprendizaje significativo, que les permite renacer. Asimismo, el rol educativo retroalimenta a quien lo ejerce: "Estos niños me inspiran. Sabía que algún día alguien tocaría mi música. Me llamo Clement Mathieu. Soy músico, y todas las noches compongo para ellos". En suma, hay una notable "coevolución" entre el profesor y sus alumnos: sin aquél, éstos no hubieran despertado sus talentos más profundos y cargarían una autoestima dañada; a la inversa, sin esos alumnos, tampoco Mathieu habría logrado sus aspiraciones más hondas: educar y crear. Por lo demás, ambas vocaciones se interpotencian: tal como una mano lava la otra, talento creador y talento educativo forman un todo indisociable, y esa dialéctica beneficia a todos.

Resulta muy ilustrativo lo que el protagonista anota en su diario tras cinco meses de trabajo: "Cada semana que pasa consigo victorias nuevas. Quizás sea una ilusión, pero hasta nuestro director parece cambiado". Y es cierto: ocasionalmente, el mismísimo Rachin muestra mejor humor: por ejemplo, al recibir en la cara un pelotazo casual, ya no castiga al "culpable", sino que se suma al juego convirtiendo un gol sorpresivo; más tarde lo vemos haciendo y lanzando avioncitos de papel, como un niño más (lamentablemente, sus cambios son episódicos).

Maduración multidimensional. Se puede decir que el quehacer artístico sanó ciertas heridas individuales y mejoró dinámicas grupales e institucionales. El avance de los alumnos abarca tanto sus capacidades cognitivas como el comportamiento interpersonal: se atenúan la hostilidad y la competencia a favor de la cooperación y la amistad, e incluso en algunos se percibe mayor madurez intrapersonal. Un buen ejemplo es lo que observa Mathieu respecto de Morhange, cuando lo perdona y le permite cantar ante la baronesa: los ojos del niño expresan una combinación de sano orgullo, alegría por el buen desempeño y hasta gratitud por el perdón.

Altruismo natural. Pero la capacidad pedagógica y el talento creativo del protagonista trasuntan algo más: su entrega genuina, que jamás deriva en monserga ni en prédica. Mathieu resignifica la oscuridad de la vida y sus adversidades, como lo sugiere el "Himno de la noche", de Rameau (1683-1764), que los niños entonan: "Oh noche, trae a la tierra / la tranquilidad de tu misterio” [// $]$ ¿Hay alguna verdad más dulce que la esperanza?” Es como si el sufrimiento entrañara cierta promesa paradójica: quien lo afronta con entereza y esperanza, recibirá profundas lecciones de vida. He ahí la clave del éxito psicopedagógico y socioterapéutico de Mathieu.

\subsection{Plano ideológico}

Las dos caras del autoritarismo. El director del colegio ilustra muy bien el carácter jánico del autoritarismo: por un lado, prepotencia para con los subalternos; por otro, actitud aduladora con el poder (como lo refleja su actitud ante la baronesa).

Secuelas de la guerra. Se vive la posguerra, pero el colegio parece congelado en los años de ocupación nazi. Por ejemplo, los niños apodaron "Calva de cromo" a Mathieu [Crane d'obus, es decir, 'cráneo de obús'], lo que equivaldría a "Cabeza de bomba". Valga otro ejemplo: cuando Mathieu les pide escribir qué deseaban ser cuando grandes, anota en su diario: "Todos tenían sueños fabulosos: dos bomberos, tres vaqueros, un domador de tigres, un piloto de caza, dos espías [...]”. Es decir, algunos veían el espionaje ¡como oficio!... 
El arte como resistencia. En esa misma línea, el coro también arroja luces indirectas sobre el contexto. Para empezar, funcionaba en un status semiclandestino, ya que los niños practicaban ocultamente y a veces en horarios extraprogramáticos (cantan de noche y en pijamas). También es significativo que en su diario el protagonista se refiera a su actividad como una revolución dentro del establecimiento, y de hecho alude al otro prefecto como si se tratara de un aliado. Vale decir, el contexto bélico gravita recursivamente sobre el internado.

Transformación de las reglas. El filme sugiere que, ante reglas ilegítimas, es posible una transformación profunda sin violencia, introduciendo ciertos cambios en distintos planos y en diversos grados. Mathieu cambia la atmósfera mediante un trato humanizado y creativo, revirtiendo la injusticia ya instalada. Rompe así la espiral de la violencia, y poco a poco van sumándose los niños y hasta miembros del personal. Maxence es el primero, pues su bonhomía y su paciencia lo convierten en aliado natural de Mathieu, y luego habrá nuevas conversiones. "Chabert me sorprendió -anota Mathieu en su diario-. Pensé que era un ferviente doble de Rachin, pero descubrí que era un buen sujeto para quien los deportes y la música eran la clave de la unidad familiar. Con su ayuda estoy organizando la resistencia. Nuestro coro es clandestino". Incluso Langlois, el distante profesor de aritmética, terminará integrándose al coro como un “niño” más.

Jerarquía de contextos. El autoritarismo, el temor y la sorda rebeldía que imperan en el internado son una metáfora de Francia durante la ocupación nazi. Extrapolado a ese contexto mayor, el arte representa una utopía libertaria e inclusiva. Por ejemplo, incorporado al coro, Langlois pide excusas si comete errores, como si ya no le importara bajar de su pedestal docente. Tal actitud reduce el verticalismo, pues el coro es un espacio colaborativo y fraternal, que posibilita una convivencia más democrática.

Ausencia de las mujeres. Los hombres son mayoritarios y predominantes; en contraste, las mujeres aparecen de modo episódico y tangencial. Esto connotaría cierto machismo, aunque no como mensaje intencional.

Simplismo y miopía institucional. La consigna del director (“acción-reacción”) remite a un conductismo caricaturesco y mal entendido, que lo reduce a la asociación automática entre estímulo y respuesta. Desde luego, tal consigna expresa una visión torpemente lineal de los hechos, pues se desentiende de la circularidad y la causalidad mutua de las interacciones. Esta miopía impide que cada cual comprenda la complejidad del sistema y los alcances de sus propias actitudes, y a la vez gatilla nuevos círculos viciosos.

La pedagogía como apostolado. En vivo contraste con ese conductismo malentendido, el protagonista encarna un modelo de pedagogía que linda en apostolado. "No tengo un hijo”, reconoce ante Violette, pero se corrige: "En realidad, tengo sesenta niños". Y de hecho es un padre sustituto para muchos de los estudiantes: por ejemplo, una noche lo vemos abrigando a un niño que se ha destapado mientras dormía, y en otra escena corregirá incluso la postura física de un alumno (las malas posturas afectan tanto los sentimientos como los aprendizajes).

\subsection{Plano simbólico}

Coro versus solo. El simbolismo del coro es complejo y sutil. Si es un sistema sano y está al servicio de la educación, un coro debería incluir y no excluir, pues requiere armonizar los aportes de todos; asimismo, el canto sugiere cierta oscilación entre trabajo y juego, entre disciplina y placer. Sin embargo, en un verdadero trabajo de equipo cada cual es necesario, 
pero no imprescindible, y así lo comprobó Morhange cuando quiso darse aires de pequeño divo. Recuérdese el solo que Morhange debía ejecutar: el joven lo aprende por su cuenta, vislumbrando que cantar un solo lo destacará sobre el resto del coro; sin embargo, cuando Morhange parece considerarse por encima del grupo, Mathieu no duda en suprimir el solo (que únicamente Morhange podía interpretar), haciéndole entender así (en un segundo nivel de comunicación) que nadie es indispensable. Empero, cuando Morhange ya parece comprender, Mathieu levanta el castigo, permitiéndole así lucirse ante la baronesa; es decir, en un tercer nivel metacomunica al joven que el talento individual es relevante, pero que el todo importa más que cada parte aislada.

Música y arte. La música genera intimidad, pues propicia tanto la autoexploración de cada personaje (hacia su interioridad y afectividad personal) como la apertura intersubjetiva. Los elementos básicos de la música (ritmo, melodía, armonía) actúan sobre la motricidad, la sensorialidad, la afectividad y el intelecto. Dada su naturaleza multidimensional, ofrece un atajo hacia las utopías. De hecho, las letras de las canciones expresan metafóricamente la función del arte y la pedagogía en aquel internado: "Como una caricia en el océano / la gaviota aterriza suavemente / en las rocas de una isla sumergida”. Al mismo tiempo, las canciones connotan el ideario del músico-profesor, casi como un recordatorio de su misión más profunda: "Ve en el camino / niños olvidados que están perdidos. / Échales una mano, / guíalos hacia horizontes nuevos, / ayúdales a entender, / siente, en la profundidad de la desesperación, / el renacer de una ola de esperanza, / el fervor de la vida”. Asimismo, otro fragmento exhorta a perseverar y sobreponerse a las dificultades: "Brisa invernal efímera, / por fin tu aliento frío se desvanece. / Lejos, en lo alto de las montañas / enfrenta al viento y despliega tus alas, / en el amanecer del este / encuentra un camino al arco iris / y la primavera se revelará ante ti. / Con calma, en el océano."

Ahora bien, en un contexto tan adverso, hasta el arte resulta sospechoso o incómodo. De hecho, el director recela del protagonista, como si su labor educativa escondiera un delito. Para alguien autoritario, la educación creativa y liberadora y creativa implica inevitablemente algún grado de desobediencia. En medio de esta tensión, resulta esperanzadora la armónica hallada junto al dinero robado por Corbin, pues muestra que incluso ese joven ladrón gustaba de la música y que también aspiraba a la belleza.

Aviones de papel. Al despedirse de Mathieu los niños le lanzan avioncitos de papel, como expresando analógicamente sueños individuales y esperanzas colectivas. Lo mismo vale para los paracaídas en miniatura y el globo aerostático con que soñaba Corbin (quien había robado el dinero). En suma, la libertad se alcanza "volando" con la imaginación.

Fuego y cigarros. Ya al inicio del filme, el fuego preanuncia tanto la transformación como la purificación. Y otro tanto ocurre hacia el final con el incendio del edificio, pues tras su destrucción será posible construir algo nuevo. A la vez, el fuego remite simbólicamente al infierno; por ejemplo, en su última discusión, Rachin le espeta a Mathieu: “iVáyase al diablo!" "No, lo dejo aquî", contesta el profesor, como queriendo decir: El infierno es este internado y usted lo ha transformado en eso al dirigirlo diabólicamente. Por otra parte, el cigarrillo parece una variante simbólica del fuego. Por ejemplo, el inadaptado Mondain fuma provocadoramente en presencia de Mathieu, y también aparece fumando en la última 
escena, lo que sugiere que fue él quien incendió el colegio². Por último, tampoco parece casual que Mouton hiriera en la muñeca a Regént -si creemos la versión de ésteprecisamente cuando le decomisó los cigarrillos.

Problemas aritméticos. Langlois plantea a sus alumnos el siguiente problema: "Una gallina pone 84 huevos al año. Bien alimentada, cuidada en un gallinero limpio y ventilado pondrá 154. ¿Cuántos huevos podría obtener un granjero de sus 9 gallinas?” Analógicamente, esto sugiere que -en condiciones adecuadas- los alumnos problemáticos desarrollarían sus potencialidades, beneficiándose a sí mismos y a la sociedad.

Nombres. Los nombres de ciertos personajes refuerzan una lectura en clave cristiana: [1] $\mathrm{El}$ apellido del protagonista (Mathieu) remite a Mateo, apóstol y evangelista (y ya vimos que él asume la docencia como un apostolado). [2] Su nombre de pila confirma el simbolismo: 'Clement' significa clemente, y la clemencia es justamente una de sus virtudes más notorias; de hecho, tiene una "paciencia de santo", incluso cuando algún alumno raya en el delito (por ejemplo, a Mondain lo echa de menos en el coro cuando es castigado con quince días de encierro tras robar el reloj al prefecto Chabert). [3] Por si las pistas anteriores no bastaran, su discípulo más talentoso se llama Pierre, que equivale a Pedro, como el discípulo de Jesús que fundó la Iglesia para evangelizar (algo ligeramente similar a lo que hará más tarde Morhange al viajar por el mundo en su condición de director de orquesta). [4] Además, el apellido Morhange parece armonizar dos opuestos: mort (muerte) y ange (ángel), antinomia que calza muy bien con cómo lo describió Régent: "Parece un ángel, pero actúa como un diablo". [5] Asimismo, tampoco parece casual que se llamara Mouton el interno que se suicidó lanzándose desde el techo, ya que el apellido se traduciría como 'oveja', símbolo clave del sacrificio cristiano. [6] En contraste, el muchacho inadaptado se apellidaba Mondain ('mundano'), como insinuando que 'el mundo' provocó su perversión. Esta última interpretación resulta congruente con el pensamiento cristiano (recuérdese la Epístola de Santiago 4:4: “¡Oh almas adúlteras! ¿No sabéis que la amistad del mundo es enemistad contra Dios? Cualquiera, pues, que quiere ser amigo del mundo, se constituye enemigo de Dios").

Por otra parte, el nombre del internado evoca tanto el tocar fondo como la idea de estancamiento (etang = estanque). El propio protagonista anota en su diario, el 15 de enero de 1949, su primer día: "Le fond de l'etang. Hasta el nombre me calzaba como guante".

\subsection{Plano estético}

Centralidad del canto. Aunque el arte elegido bien pudo ser otro (literatura, pintura, escultura, teatro), el canto ofrece simbolismos propios: está al alcance de cualquiera y no requiere instrumentos; es decir, incluye e integra. Así, la película muestra que el arte vivifica la vida individual, la interpersonal y la comunitaria.

Elementos alusivos. Las letras de las canciones son alusivas y metafóricas, como apelando a mayor optimismo para contrarrestar la desesperanza. Además, fotos, locaciones y paisajes exteriores tienen mucha luz y claridad, lo que también sugiere optimismo.

Intertextualidad. La historia no es estrictamente original, y algunos pasajes evocan películas previas y posteriores (ver apartado 5.2). Es como si el filme integrara otro "coro"

\footnotetext{
2 Mientras impartía um curso en el Magister de Desarrollo Cognitivo, la alumna Viviana de Simone hizo notar que también se podría considerar simbólico que Mondain sea colorín, porque ello refuerza visualmente su relación con el fuego. Agradezco y acojo su comentario.
} 
mayor, consagrado a la comunicación profunda antes que a exhibir originalidades deslumbrantes.

Astucias del guion. El filme interrumpe ciertas escenas que, de prolongarse, entramparían al protagonista. Por ejemplo, la provocación de Mondain no llega más allá, porque suena la campana; asimismo, cuando el protagonista discute con el director y la tensión llega a un punto de no retorno, el director debe retirarse porque lo esperan en la sala de visitas. Con todo, tales elusiones no merman el impacto emocional.

Actuación. Aunque lo recién apuntado afecta ligeramente la verosimilitud, las actuaciones sí resultan convincentes. Y es que, más allá de sus posibles limitaciones, se trata de una historia bien narrada, conmovedora y optimista.

Cine como socioterapia. Al igual que otras películas afines, Los coristas ofrece una visión cruda, pero también esperanzadora. Curiosamente, en varios de estos casos el profesor no es un profesional de la pedagogía, sino más bien alguien con vocación de formador y casi de socioterapeuta (pero abordar esto último requeriría un artículo aparte).

\section{Reflexiones metacríticas}

Más que examinar Los coristas para descifrar mensajes ocultos, este escrito procura discernir sus lecciones implícitas. Y he ahí lo más relevante: desafiar la perspicacia de los estudiantes, pero también la propia, pues ello favorece el aprendizaje vicarial $u$ observacional. En suma, el objetivo primordial es fomentar la sensibilidad, la capacidad de extraer enseñanzas y la mutualidad del aprendizaje.

Compatibilidad con otros enfoques. Nuestro esfuerzo es similar a los que el new criticism, el psicoanálisis y luego el estructuralismo solían desplegar ante obras particulares. En principio, tanto la "lectura en profundidad" (close reading) como el análisis estructural y el freudiano parecen hoy "superados" por otros enfoques; no obstante, los conocimientos y las habilidades que todos esos métodos ponen en juego (perspicacia, razonamiento, argumentación, pensamiento crítico) siguen siendo tanto o más necesarios que antes, de modo que convendría rescatar su virtualidad pedagógica. Y puesto que muchos jóvenes están hoy más cerca de la pantalla que del texto impreso, el análisis psicofílmico permite motivarlos a mejorar la comprensión como actitud general y como aptitud transversal.

Desde la compatibilidad a la consiliencia. Reivindicando métodos previos -y otros más actuales, como la hermenéutica, los estudios culturales, la ecocrítica, la sociocrítica y la narratología cognitiva-, podemos transitar hacia la consiliencia, es decir, la voluntad de integración interdisciplinar para promover pensamiento organizado. Por ejemplo, desde la perspectiva de la Educación por el Arte, resulta ya perentorio integrar enfoques que difieren en ciertos aspectos, pero que al cabo prueban ser compatibles (Gardner, 1994). Así, la pedagogía, las humanidades, la psicología y las ciencias humanas bien pueden reivindicar nexos naturales con el trabajo artístico. Por lo demás, promover la sensibilidad y la creatividad resulta provechoso en la enseñanza de cualquier asignatura, desde la enseñanza básica hasta la universitaria.

Extrapolación. En un tercer nivel, los filmes resultan inspiradores también para quienes enseñan disciplinas no artísticas. Por ejemplo, la Enseñanza para la Comprensión (propuesta por Gardner y Perkins y desarrollada por diversos colaboradores) distingue cuatro niveles de comprensión -ingenua, de principiante, de aprendiz y de maestro-, que 
se pueden apreciar en cuatro dimensiones: contenidos, objetivos, procedimientos y productos (ver Stone, 1999). Pues bien, los niños de Los coristas mostraban al inicio tanto descompromiso, desmotivación e incluso hostilidad, que cabría postular un nivel "cero", inferior incluso al que dicha teoría llama "comprensión ingenua”; pero su participación en el coro les permite superarse y profundizar tanto su comprensión como su compromiso. Por lo mismo, desentrañar las claves de una enseñanza tan exitosa constituye un desafío moral y cívico.

La maduración integral. Aplicando un enfoque cognitivo-evolutivo, Michael J. Parsons (2002) mostró que el juicio estético también evoluciona en etapas, como la inteligencia (según Piaget) y el juicio moral (Kohlberg). Pues bien, el análisis psicofílmico (abierto a cualquier clase de filmes) ofrece enormes posibilidades para estimular simultáneamente el desarrollo de tres dimensiones (cognitiva, moral, estética), y al mismo tiempo propicia una cuarta: la dimensión cívica. En efecto, visionando y comentando en grupo un filme, niños y jóvenes interiorizan gradualmente la necesidad de una disciplina personal, y de paso aprenden a explorar sus psiquismos individuales respetando al mismo tiempo el psiquismo ajeno.

Arte terapia y socioterapia. Así, el arte no es un ámbito en que la subjetividad retoza autocontemplándose; antes bien, tiende un puente hacia la intersubjetividad, ese horizonte indispensable de cualquier ética y espiritualidad maduras. En suma, explorar en grupo un filme no induce ensimismamiento; al contrario, favorece la escucha activa (pues los otros suelen tener perspectivas muy diversas), fomenta la buena argumentación (ya que debemos razonar correcta y claramente si queremos comunicar a otros una inferencia o una interpretación plausible) y favorece el trabajo en equipo.

Musicoterapia avant la lettre. La película está ambientada en la segunda posguerra, cuando la musicoterapia estaba por nacer (Thayer Gaston, 1989; Ballesteros, 2010). Y es notable la coincidencia entre la conducta del protagonista y la sugerida por los especialistas en musicoterapia (véase Lacárcel Moreno, 1995; Gento Palacio y Lago Castro, 2012). En tal sentido, Mathieu revela no solo vocación pedagógica, sino también la intuición de un precursor. Curiosamente, el director tiene cierto parecido con el protagonista, pues su propia soledad lo tornó sensible respecto al abandono y la vulnerabilidad de otros. De hecho, en una entrevista confidenció: "Tuve una infancia herida: mis padres se divorciaron cuando yo era pequeño. Además, eran actores y apenas los veía, así que me crio mi abuela. Muchas veces me encontraba contándome historias a mí mismo. En cierta manera, ya escribía películas. Conservo cierta nostalgia, no del pasado, sino de la infancia. Cuando hago este tipo de películas, tengo la sensación de convertirme en un niño" (citado por Niño González y González Vallés, 2017, p. 307).

En definitiva, el buen arte suele ser sublimatorio antes que compensatorio o meramente catártico.

\section{Análisis psicofílmico y educación inclusiva}

El análisis del filme (apartado 2) y las reflexiones subsiguientes (apartado 3) apuntaron a desafíos frecuentes en la enseñanza especial e inclusiva (ver Mara Sapon-Chevin 2012). En este nuevo apartado ofrezco otras sugerencias más concretas. 


\subsection{Reivindicación socioeducativa del cine en el nuevo contexto sociocultural}

Hace algunas décadas, los medios audiovisuales suscitaron grandes esperanzas entre los educadores, pues posibilitaban múltiples aplicaciones; irónicamente, hoy las pantallas y los teléfonos celulares dificultan en grado extremo el ejercicio docente. En tal contexto, el cine ofrece un puente entre esas esperanzas y los nuevos retos (globalización, interculturalidad, desigualdad). Desde luego, numerosos filmes muestran crudos contextos socioeducativos: Los cuatrocientos golpes, Francia, 1959; La guerra de los botones, Francia, 1962; Al maestro con cariño, Reino Unido, 1967; Contra corriente $[U p$ the Down Staircase], EE.UU., 1967), entre los más antiguos. Más recientemente, cabe mencionar Cinema Paradiso, Italia, 1988; Con ganas de triunfar [Stand and deliver], EE.UU., 1988, que muestra la destreza pedagógica y la enorme entrega de un ingeniero que decide enseñar matemáticas en un contexto vulnerable y hostil; La sociedad de los poetas muertos, EE.UU., 1989; Un lugar en el mundo, Argentina, 1992; América X, EE.UU.,1998; La lengua de las mariposas, España, 1999; El color del paraíso, Irán, 1999 (bellísimo filme sobre un niño ciego); Ni uno menos, China, 1999; El Bola, España, 2000; Machuca, Chile, 2004; Los grandes debatientes, EE.UU., 2007; La ola, Alemania, 2008; La clase o Entre muros, Francia, 2008; Profesor Lazhar, Canadá, 2011. La lista podría extenderse mucho más, pues numerosas películas tienen alcances educativos, y visionarlas en grupo resultará grato y fructífero en varios niveles.

Pese las muchas bondades del cine como recurso educativo, algunas de las enciclopedias más recientes apenas lo aluden y no le dedican entradas o artículos especiales (es el caso de Reynolds y Fletcher-Janzen, 2007; Banks, 2012, y Kumar Goes, 2015).

\subsection{La educación en sentido amplio}

Más allá de la educación institucionalizada y formal, el cine muestra también muchas situaciones de aprendizaje no formal. Por ejemplo, visionar en grupo 12 hombres en pugna (EEUU, 1957) permitirá apreciar vívidamente cómo un personaje -combinando buenos argumentos, asertividad y cortesía- logra cambiar la opinión de otros doce integrantes de un jurado estadounidense, quienes consideraban natural y "justo" condenar al aparente culpable. Asimismo, si se quiere promover una reflexión acerca de las implicancias insospechadas de los teléfonos celulares, sugiero visionar Perfectos desconocidos (Italia, 2016). Los ejemplos se multiplican por mil.

\subsection{Conflictos sociocognitivos}

Aparte de los conflictos motivados por diferencias de personalidad, la psicología social de la educación ha puesto de relieve la importancia de otros que surgen cuando dos o más personas afrontan un mismo problema, pero abordándolo desde perspectivas diferentes o con métodos e incluso actitudes notoriamente disímiles. El caso prototípico involucra a dos niños que discrepan sobre una situación porque difieren en su desarrollo cognitivo; empero, los conflictos sociocognitivos también surgen por la diversidad intercultural, de géneros y hasta de estilos cognitivos. En el caso del cine, los estudiantes suelen evaluar de modos muy divergentes las conductas de ciertos personajes o la calidad de la película, precisamente porque difieren en su aproximación a la misma; por ejemplo, algunos se centran en aspectos estéticos -visuales, musicales, actorales, narrativos-, mientras otros atienden principalmente a diálogos, mensajes ideológicos o valores; asimismo, mientras algunos hacen inferencias iluminadoras, otros proponen interpretaciones plausibles. Pues bien, el desafío consiste en motivar la participación, procurando que todos vayan 
reconociendo y aprovechando los aportes más significativos (que no necesitan ser expresados en muchas palabras ni menos con ostentación). Para aprovechar educativamente las discrepancias, conviene fomentar la deliberación razonada (no la disputa), y distinguir siempre entre falacias y argumentos.

\subsection{Metacognición y sociocognición}

Aprovechar educativamente los conflictos sociocognitivos es una capacidad pedagógica de primer orden, que requiere integrar tanto conocimientos y metaconocimientos (Fourez, 1998) como también habilidades (análisis, síntesis, argumentación, explicación) y actitudes (apertura, respeto, amabilidad). Ahora bien, aplicando con pertinencia las distinciones introducidas y ejemplificadas en este escrito (sobre todo las seis dimensiones y los seis niveles de análisis), mejoraremos tanto los procesos de aprendizaje como sus resultados. Inicialmente, algunos tienen dificultad para distinguir entre opinar y argumentar; por lo mismo, conviene detenerse en los tres niveles iniciales de análisis (descripción, inferencia, interpretación), porque son requisitos para avanzar hacia los tres siguientes (valoración, introspección, creación). Conviene entonces partir por observaciones progresivamente más perspicaces; luego, intentar algunas inferencias iluminadoras; finalmente, formular interpretaciones (que siempre deben ser plausibles) solo cuando algo siga resultando enigmático y requiera explicaciones adicionales.

Aunque trascender el simplismo enriquece a todos, algunos estudiantes pueden sentirlo como una amenaza. Sin embargo, incluso los más refractarios suelen acoger bien los comentarios relevantes (observaciones agudas, inferencias iluminadoras, interpretaciones plausibles, explicaciones nítidas, argumentos convincentes), pues mejoran la comprensión de todos. Es como si cada participante se sintiera impelido a dar lo mejor de sí para reciprocar el aporte que recibieron.

\subsection{Complejidad e integración de los opuestos}

En tal sentido, el análisis psicofílmico propicia la productividad individual y la colectiva, la maduración cognitiva y la socioemocional, el pensamiento convergente y el divergente, la lucidez y la sensibilidad, el raciocinio y la imaginación, la lógica y la creatividad. Examinar en grupo un buen filme puede despertar vocaciones científicas, artísticas, cívicas e incluso espirituales, y siempre permite la autoexploración.

Para ello, conviene motivar a los estudiantes a investigar los sesgos perceptuales, los prejuicios cognitivos, los heurísticos erróneos, los paralogismos, las falacias y los sorprendentes hallazgos acerca del autoengaño y sus múltiples variantes (aunque la bibliografía es cuantiosa, Helena Matute 2018 ofrece un buen resumen).

\subsection{Algunos énfasis}

Véase en el cuadro 1 el cruce de las seis dimensiones o planos de exploración (eje horizontal) y los seis niveles de profundidad progresiva (eje vertical) (cuadro1).

Por cierto, lo ideal es hilvanar progresivamente los comentarios, articulando así tanto las dimensiones como los diferentes niveles. Aunque recorrer todas las celdillas requiere considerable atención, muchos estudiantes se entretienen y casi no sienten el esfuerzo. Sin duda, cada docente hará bien en enfatizar especialmente algunas dimensiones, pero procurando siempre motivar, enseñar e integrar. Asimismo, el método brinda muchas ocasiones para cumplir al mismo tiempo tres objetivos propios de la educación efectiva: explicar, aplicar e implicar. Ya es bastante. 
Cuadro 1. Matriz de dimensiones y niveles de abordaje

\begin{tabular}{llll}
\hline \multicolumn{1}{c}{ INTERPERS. } & INTRAPERS. & TRANSPERS. & IDEOLÓG. SIMBÓL. ESTÉT. \\
\hline Descriptivo & & \\
\hline Inferencial & \\
\hline Interpretativo & \\
\hline Valorativo & \\
\hline Introspectivo & \\
\hline Heurístico & \\
\hline Fuente: Recuperado de Llanos $(2017 \mathrm{a}$, p. 412$)$.
\end{tabular}

\section{Referencias}

Ballesteros, R. (2010). Musicoterapia y psicología aplicadas al duelo y la pérdida. Recuperado de http://www.raquelballesteros.com/wp-content/uploads/2017/08/Musicoterapia-en-elDuelo.pdf

Banks, J. A. (2012). Encyclopedia of diversity in education. Los Ángeles, CA: Sage Publications.

Fourez, G. (1998). Saber sobre nuestros saberes: Un léxico epistemológico para la enseñanza. Buenos Aires: Ediciones Colihue.

Gardner, H. (1994). Educación artística y desarrollo humano. Barcelona: Paidós.

Gento Palacios, S. y Lago Castro, P. (2012). La musicoterapia en el tratamiento educativo de la diversidad. Madrid: UNED.

Lacárcel Moreno, J. (1995). Musicoterapia en educación especial. Murcia: Universidad de Murcia.

Llanos, E. (2002). Para un análisis psicocinematográfico integral. Gaceta de Psiquiatría Universitaria, 4, 492-500.

Llanos, E. (2016). ¿A quién ama Gilbert Grape? Gaceta de Psiquiatría Universitaria, 6(3), 351-363.

Llanos, E. (2017a). Niños del cielo. Análisis socioeducativo de un filme iraní. Revista Polis, 3, 385406.

Llanos, E. (2017b). Meta-literature and meta-art in the taste of others. En P. Baldwin (Ed.), Telling and re-telling stories: Studies on literary adaptation to film (pp. 243-259). Londres: Cambridge Scholars Publishing.

González, J. y González Vallés, E. (2017). La función pedagógica dentro de la narrativa audiovisual: Los chicos del coro. En J. Rodríguez Terceño (Ed.), La imagen de los docentes en el cine (pp. 231-145). Madrid: Asociación Cultural y Científica Iberoamericana.

Parsons, M. J. (2002). Cómo entendemos el arte. Una experiencia cognitivo-evolutiva de la experiencia estética. Barcelona: Paidós.

Reynolds, C. (2007). Encyclopedia of special education: A reference for the education of children, adolescents, and adults with disabilities and other exceptional individuals. Trenton, NJ: John Wiley \& Sons.

Stone Wiske, M. (1999). La enseñanza para la comprensión. Vinculación entre la investigación y la práctica. Buenos Aires: Paidós.

Thayer Gaston, E. (1989). Tratado de musicoterapia. Buenos Aires: Paidós. 


\section{Breve CV del autor}

\section{Eduardo Llanos Melussa}

Psicólogo por la Universidad de Chile y Doctor en Psicología y Educación por la Universidad de Granada. Ha enseñado durante casi cuatro décadas Psicología de la Comunicación, y ha recibido diversos premios por su trabajo docente. Asimismo, ha obtenido nacionales e internacionales por su obra poética. Escribe e investiga articulaciones entre creatividad, pragmática, cine y educación. Promueve la metacognición y el metaaprendizaje mediante el modelo de análisis psicocinematográfico (o psicofílmico) y también a través de comentarios psicopragmáticos de narraciones y microcuentos. ORCID ID: https://orcid.org/0000-0002-6334-3065. Email: eduardo.llanos@udp.cl 